\title{
Theoretical estimation of efficiency defect in Vapour Compression Refrigeration system using R1234yf, R134a and R1234ze
}

\author{
Shubham Soni ${ }^{1, *}$, Punit Mishra ${ }^{2}$, Govind Maheshwari ${ }^{3}$ and Devendra $S$ Verma ${ }^{4}$ \\ ${ }^{1,2} \mathrm{PhD}$ Scholar,Devi Ahilya University, Khandwa road , Indore (M.P), 452017, India \\ ${ }^{3,4}$ Department of Mechanical Engineering, Devi Ahilya University, Khandwa road , Indore (M.P), 452017, India
}

\begin{abstract}
In presented work, researchers have used efficiency defect as a tool for checking the utility of different refrigerants in Vapour compression refrigeration system. A mathematical model of simple Vapour compression refrigeration system is created. Using first law analysis and exergy analysis efficiency defect is calculated for various components of the system individually and whole vapour compression refrigeration system as well. It is found that R1234yf has highest value of efficiency defect for whole system, whereas R134a has least value of efficiency defect for whole system. Variation of efficiency defect of various components with evaporator temperature is also presented as graphs.
\end{abstract}

\section{Introduction}

Refrigerant selection is a complex task as it depends on many factors like toxicity, cost, availability, refrigeration effect etc. Over past two decades, the criteria of refrigerant selection have however shifted to parameters like Global warming potential (GWP) and Ozone depletion potential (ODP) [14]. In twenty first centaury exergy analysis has gained popularity over energy analysis $[11,12]$ as a tool for analysis of refrigeration system. Some researchers used an additional parameter of exergy analysis, known as efficiency defect, which can be used for determining the utility of refrigerants in given system[3,8] In the given work the researchers created a mathematical model of simple vapour compression refrigeration (VCR) system and conducted its exergy analysis. The results of exergy analysis helped in finding the efficiency defect value for various components of VCR system individually and VCR system as whole. The efficiency defect variation of compressor, condenser, expansion valve and evaporator with evaporator temperature is presented in the form of graphs.

\section{Energy analysis and exergy analysis}

VCR cycle is represented in figure 1. Its p-h plot is shown in fig 2 . The plots represent that compression is

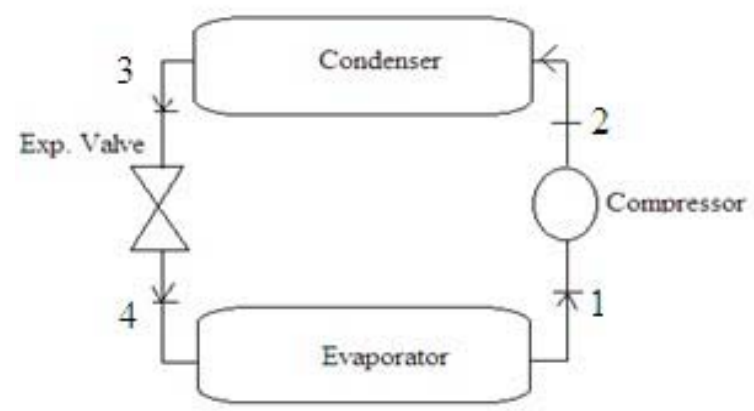

not isentropic. The compressor efficiency is considered $80 \%[5]$.

Fig.1 Schematic of VCR system

\subsection{Energy Analysis}

By applying Steady flow Energy Equation (SFEE) on each component of VCR cycle individually, the energy balance equations are deduced as $[2,3]$

\footnotetext{
* Shubham Soni: er.soni.shubham@gmail.com
} 


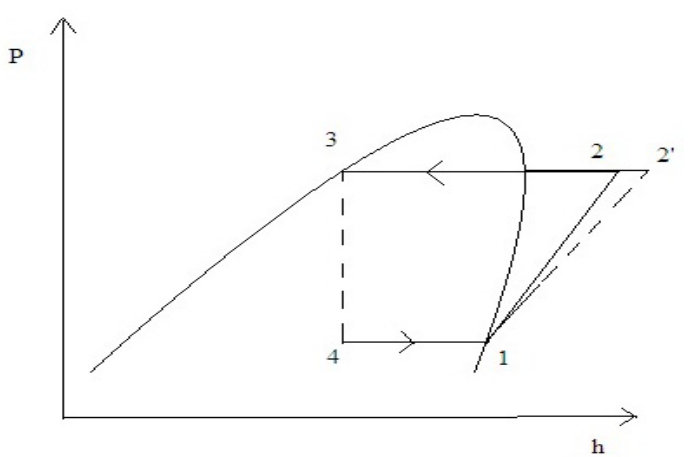

Fig.2. p-h plot of VCR cycle with irreversible compression

a. Work consumed in compressor $(W c)$

$$
W c=m\left(h_{1}-h_{2}\right)
$$

b. Heat rejected in Condenser $\left(Q_{c}\right)$

$$
Q_{c}=m\left(h_{2}-h_{3}\right)
$$

c. For Expansion Valve

$$
h_{3}=h_{4}
$$

d. Heat absorbed in Evaporator $\left(Q_{e}\right)$

$$
Q_{e}=m\left(h_{1}-h_{4}\right)
$$

Where $m$ is refrigerant flow rate and $h$ is specific enthalpy. The performance of VCR system is given by coefficient of performance (COP). It is ratio of refrigeration effect obtained for given work input. [4]

$$
C O P=Q_{e} / W_{c}
$$

\subsection{Exergy Analysis}

Exergy destruction $\left(\mathrm{E}_{\mathrm{xd}}\right)$ for various components is calculated from the following equations $[9,10]$

\section{e. Exergy destruction in Compressor

$$
E_{x d 1-2}=m T_{o}\left(s_{2}-s_{1}\right)
$$

f. Exergy destruction in Condenser

$$
E_{x d 2-3}=m T_{o}\left(s_{3}-s_{2}+q_{d} / T_{c}\right)
$$

g. Exergy destruction in Expansion Valve

$$
E_{x d 3-4}=m T_{o}\left(s_{4}-s_{3}\right)
$$

h. Exergy destruction in Evaporator

$$
E_{x d 4-1}=m T_{o}\left(s_{1}-s_{4}-q_{e} / T_{e}\right)
$$

Total destruction of exergy ( $E_{x d}$ total $)$ is sum of exergy destroyed in each component. It is given by the equation $[6,7]$

$E_{x d \text { total }}=E_{x d 1-2}+E_{x d 2-3}+E_{x d 3-4}+E_{x d 4-1}$

\section{Efficiency defect}

It is a very important parameter for analyzing refrigeration systems having multiple components. It is given as the amount of exergy destroyed in a particular component due to irreversibility to the work supplied in compressor. Thus it gives that fraction of exergy given to system which is destroyed in any component due to irreversibility [8]

$$
\delta_{i}=\frac{E_{x d i}}{W_{c}}
$$

Where i represent the particular component and $W_{c}$ is compressor work input.

\section{Results and Discussion}

Data assumed for calculation of results are mentioned here
1. Refrigerant flow rate
(m):
$1 \mathrm{kgs}^{-1}$
2. Isentropic efficiency of compressor:
$80 \%$
3. Temperature range of evaporator (Te): 263 - $271 \mathrm{~K}$
4. Temperature of condenser (Tc):
$323 \mathrm{~K}$
5. Dead state temperature (To):
$303 \mathrm{~K}$

Using equations from (1) to (10) destruction of exergy in various components of VCR system is calculated along with compressor work. From equation (11), efficiency defect of individual components and whole system is calculated. Results obtained are presented in table 1.

Table 1 Efficiency defect in various components of simple VCR system for different refrigerants

\begin{tabular}{|l|l|l|l|l|}
\hline Refrigerant & Compressor & Condenser & $\begin{array}{l}\text { Expansi } \\
\text { on Valve }\end{array}$ & Evaporator \\
\hline R134a & 0.18134 & 0.00316 & 0.22 & 0.000827 \\
\hline R1234yf & 0.18751 & 0.00177 & 0.2743 & 0.0006515 \\
\hline R1234ze & 0.1863 & 0.0029 & 0.233 & 0.000723 \\
\hline
\end{tabular}

Table 2 Efficiency defect of complete VCR system for different refrigerants

\begin{tabular}{|c|c|c|}
\hline R134a & R1234yf & R1234ze \\
\hline 0.4053 & 0.4642 & 0.42292 \\
\hline
\end{tabular}

Table 3 Thermodynamic properties

\begin{tabular}{|l|l|l|l|l|}
\hline Refrigerant & GWP & ODP & $\begin{array}{l}\text { Critical } \\
\text { temperature }\end{array}$ & $\begin{array}{l}\text { Critical } \\
\text { Pressure }\end{array}$ \\
\hline R134a & 1300 & 0 & 101.06 & 40.59 bar \\
\hline R1234yf & 0 & 0 & $94.7^{\circ} \mathrm{C}$ & $33.82 \mathrm{bar}$ \\
\hline R1234ze & 1 & 0 & $109.36^{\circ} \mathrm{C}$ & 36.34 bar \\
\hline
\end{tabular}




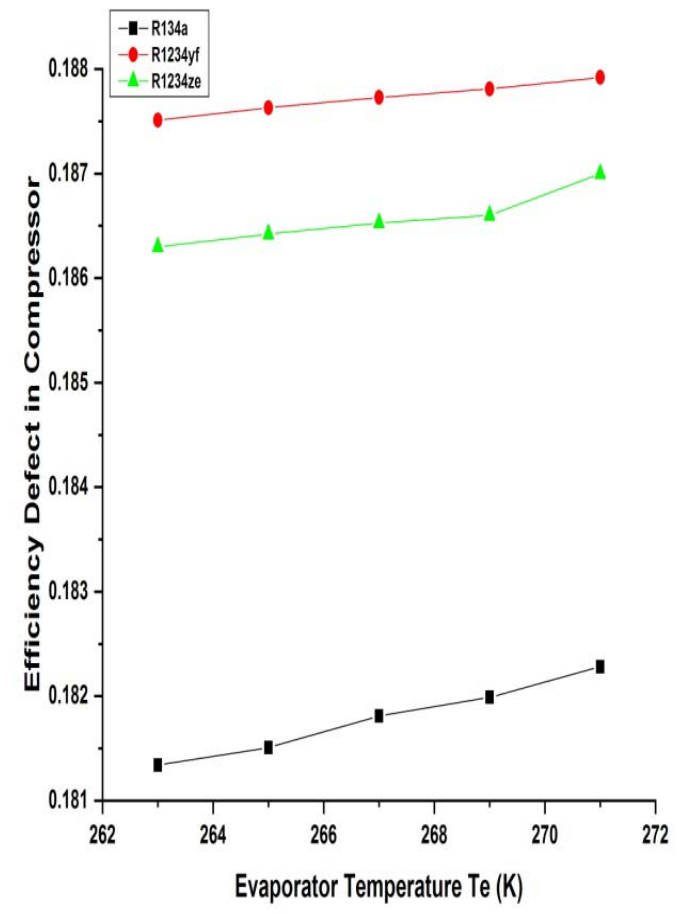

Fig 3 Compressor efficiency defect vs evaporator temperature

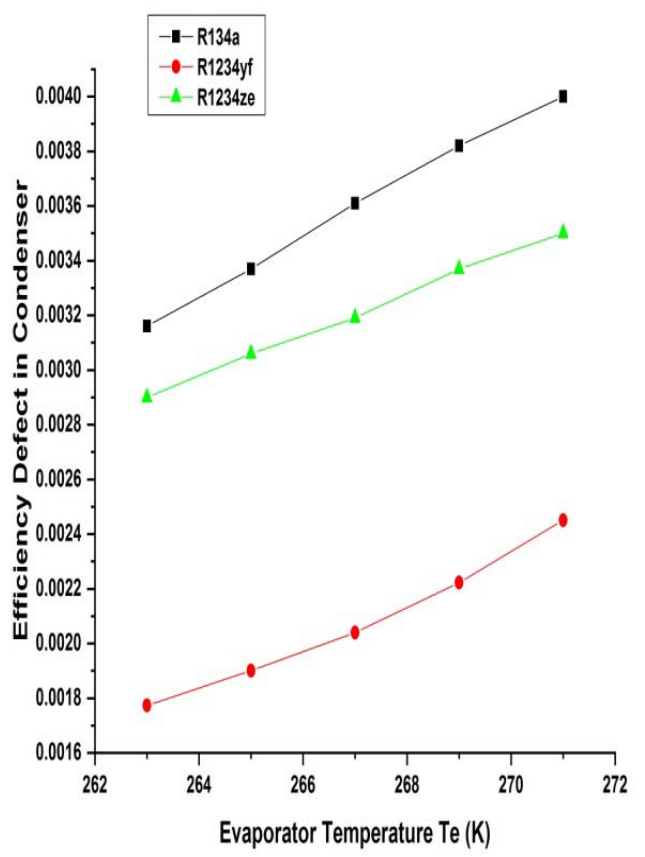

Fig 4 Condenser efficiency defect in vs evaporator temperature

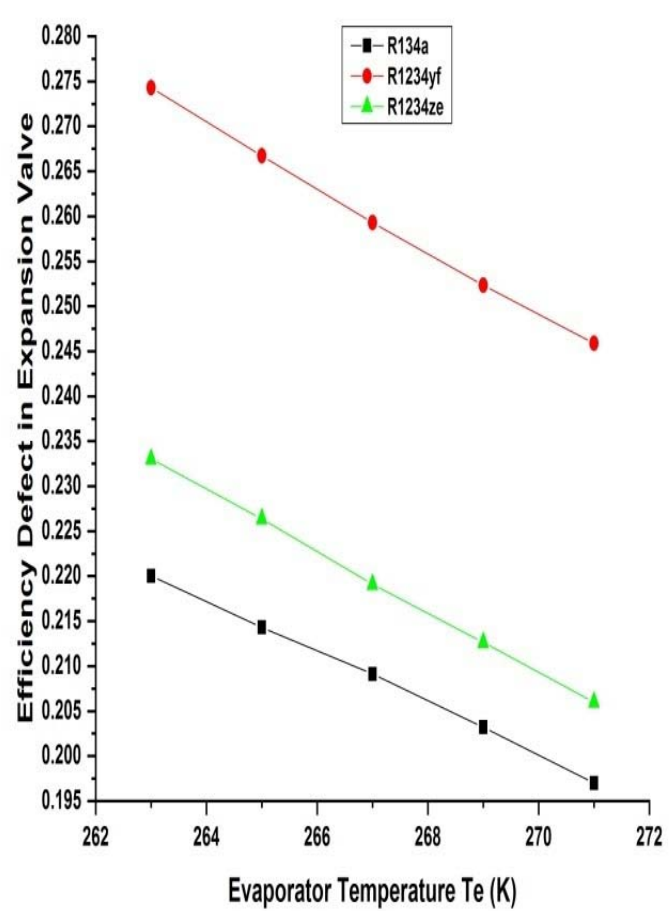

Fig 5 Expansion valve efficiency defect vs evaporator temperature

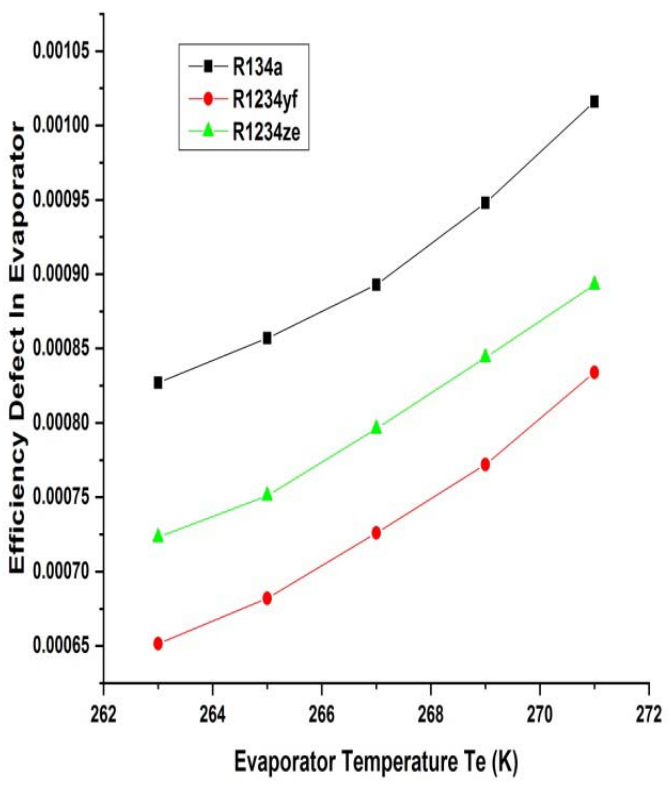

Fig 6 Evaporator efficiency defect vs evaporator temperature 
It is seen from table 2 and fig 7 that maximum efficiency defect is obtained for R1234yf which is $14.532 \%$ and $9.76 \%$ higher than efficiency defect for R134a and R1234ze respectively. When it comes to individual components, expansion valve has highest efficiency defect for all the chosen refrigerants. For compressor R1234yf has highest efficiency defect and it is 3.40\% and $0.649 \%$ higher than that obtained for R134a and R1234ze respectively. For condenser R134a has highest efficiency defect and it is $8.965 \%$ and $78.53 \%$ higher than that obtained for R1234ze and R1234yf respectively. In case of expansion valve R1234yf has highest efficiency defect which is $24.68 \%$ and $17.725 \%$ higher than that obtained for R134a and R1234ze respectively. In evaporator highest efficiency defect is obtained for R134a, which is $26.93 \%$ and 14.384\%higher than obtained for R1234yf and R1234ze respectively. Variation of Efficiency defect in various components of VCR system with evaporator temperature is presented from fig 3 to fig 6 . From Fig 7 it is clear that the maximum and minimum efficiency defect is obtained for R1234yf and R134a respectively.

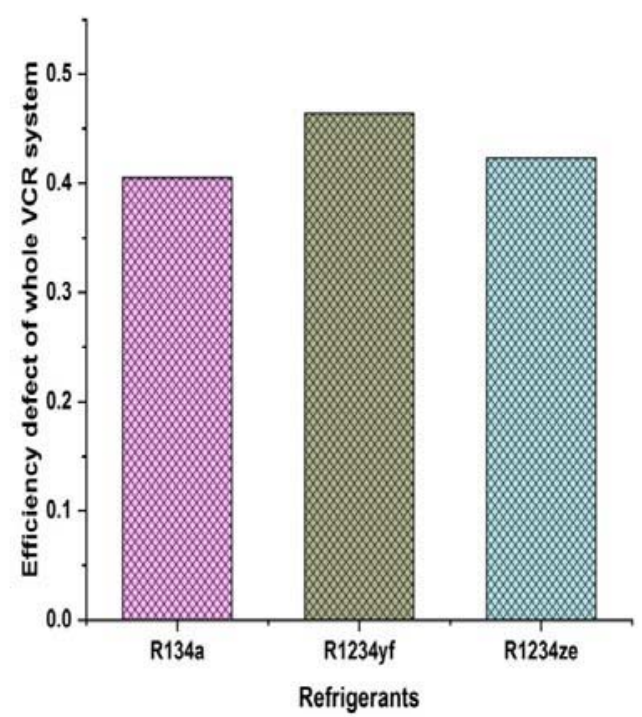

Fig 7 Efficiency defect of whole VCR system for different refrigerants

\section{Conclusions}

Based on results obtained these conclusions can be derived. R1234yf and R1234ze may have negligible global warming potential as compared to R134a, but R134a has least total efficiency defect among all three refrigerants. However R1234ze lags behind R134a by very little margin of $4.347 \%$.Efficiency defect in compressor, condenser and evaporator increases with evaporator temperature but efficiency defect in expansion valve reduces with increase in temperature of evaporator. Highest and least efficiency defect for compressor and expansion valve is obtained for R1234yf and R134a respectively. Highest and least efficiency defect in condenser and evaporator is obtained for R134a and R1234yf respectively. All the chosen refrigerants have certain pros and cons, but if ODP and GWP are not to be considered, in that case efficiency defect can be taken as one of the parameters of refrigerant selection.

\section{Nomenclature}

$\begin{array}{ll}T_{c} & \text { Temperature of condenser } \\ T_{e} & \text { Temperature of evaporator } \\ S & \text { Specific entropy } \\ E_{x d} & \text { Exergy destruction } \\ \delta & \text { Efficiency defect }\end{array}$

\section{References}

[1] United Nations Environmental Program, Montreal Protocol on substances that deplete the ozone layer, Final act (1987) New York: United Nations.

[2] R.B. Jeema, R. Mansouri, I. Boukholda, A. Bellagi, International Journal of Hydrogen Energy XXX (2016) I-II.

[3] C.H. Paula, W.M. Duarte, T.T.M. Rocha, R.N. Oliveria, A.A.T. Maia, Int. Journal of Refrigeration 113 (2020) $10-20$.

[4] A. Arora, S.C. Kaushik, Int. Journal of Refrigeration.3I (2008) 998-1005.

[5] A. Arora, S.C. Kaushik , International journal of Energy research 34 (2010) 907-923.

[6] D.C. Anta, L.N. Andre, J.C. Gil , D. Sanchez ,R. Cabello, Results in engineering (2019).

[7] J.U. Ahmed , R. Saidur, S.S. Masjuki, Renewable and Sustainable Energy Reviews 15(2011) 1593-1600.

[8] C.P. Arora, Refrigeration and Air Conditioning third Edition, Tata-McGraw-Hill limited- New Delhi (2009).

[9] I. Dincer, M. Konoglu, Refrigeration Systems and Applications, Second Edition, John Willey and sons limited (2010).

[10] J.M.B. Flores, V.H.R. Hernandez, S. Uson, C.R. Maya, ENERGY (2017).

[11] N. Agrawal ,S. Patil, International conference on RAAR, Energy Procedia 109(2017) 425 - 430.

[12] A.M. Babiloni, J.N. Esbri, A. Barragan, F. Moles, Applied Thermal Engineering (2014) 259-265.

[13] C.S. Chaudhari, S.N. Sapali, Int. conference on RAAR Energy Procedia 109 (2017) 346 - 352.

[14] C.H. Paula, W.M. Duarte, T.T.M. Rocha, R.N. Oliveria, A.A.T. Maia, Int. Journal of Refrigeration 113 (2020). 